\title{
The Central Italy 2016-2017 seismic sequence: site response analysis based on seismological data in the Arquata del Tronto-Montegallo municipalities
}

\author{
Giovanna Laurenzano $^{1}$ (D) Carla Barnaba ${ }^{1}$ - Maria Adelaide Romano ${ }^{1}$. \\ Enrico Priolo $^{1} \cdot$ Michele Bertoni $^{1} \cdot$ Pier Luigi Bragato $^{1} \cdot$ Paolo Comelli $^{1}$. \\ Ilaria Dreossi ${ }^{1} \cdot$ Marco Garbin $^{1}$
}

Received: 1 June 2017 / Accepted: 19 March 2018 / Published online: 6 April 2018

(C) The Author(s) 2018

\begin{abstract}
In this paper we evaluate the local seismic response for thirteen sites located in the municipalities of Arquata del Tronto and Montegallo, two areas which suffered heavy damage during the Mw 6.0 and Mw 5.4 earthquakes which struck Central Italy on August 24,2016 . The input dataset is made by ground motion recordings of 348 events occurred during the sequence. The spectral site response is estimated by the Generalized Inversion Technique and makes use of reference sites. The interpretation is further improved through the information provided by a reference-site independent method (i.e., the so called Receiver-Function Technique) and by the Horizontal-to-Vertical Spectral Ratios of ambient noise recordings. We also provide an independent estimate of the local amplification by comparing the Peak Ground Velocity and the Spectral Amplitudes observed at each site to the value estimated by well-established Ground Motion Prediction Equations for a rock-class site. The results obtained by the adopted methodologies are all highly consistent, and they emphasize the different seismic behavior of several sites at local scale. Thus, sites located on Quaternary deposits overlying the bedrock, such as Castro, Pretare, Spelonga, Pescara del Tronto, and Capodacqua feature some relevant amplifications in a medium $(2-10 \mathrm{~Hz})$ frequency range; two sites at Spelonga show amplifications also at low frequencies; three sites located on stiff formations, i.e. Uscerno, Balzo and Colle d'Arquata, respectively, feature either nearly neutral response or low amplification level. A probable topographic effect was identified at the rock site of Rocca di Arquata (MZ80).
\end{abstract}

Keywords Local seismic response - Amatrice earthquake · Central Italy earthquake · Microzonation $\cdot$ GIT $\cdot$ EHV $\cdot \mathrm{NHV} \cdot \mathrm{PGV}$

Giovanna Laurenzano glaurenzano@inogs.it

Istituto Nazionale di Oceanografia e di Geofisica Sperimentale (OGS) - Sezione Scientifica Centro di Ricerche Sismologiche (CRS), Udine, Trieste, Italy 


\section{Introduction}

Few weeks after the beginning of the seismic sequence in Central Italy, started with the Mw 6.0 earthquake on August 24, 2016 01:36 (UTC), the Department of Civil Protection (Dipartimento di Protezione Civile, DPC; www.protezionecivile.gov.it) commissioned the Center for Seismic Microzonation and its applications (Centro di Microzonazione Sismica e sue applicazioni, CMS; www.centromicrozonazionesismica.it) to coordinate a series of geophysical, geomorphological, geological, and geotechnical surveys, with the final goal of performing a Level 3 seismic microzonation (Working Group SM 2008) in some localities of the most damaged municipalities of the epicentral area.

The National Institute of Oceanography and Experimental Geophysics (Istituto Nazionale di Oceanografia e di Geofisica Sperimentale, OGS; www.inogs.it), as a member of CMS, contributed to this initiative through the installation of a temporary network of thirteen seismological stations in the two municipalities of Arquata del Tronto and Montegallo, located in the Ascoli Piceno Province (Marche Region, Italy), with the aim of evaluating the local seismic response at the instrumented sites.

The evaluation of the seismic spectral response under earthquake excitation (i.e. the site response) represents a main step towards an accurate quantification of the seismic hazard and is a fundamental step of the Level 3 seismic microzonation, i.e. the partition of the investigated area into micro-zones featuring similar behavior to earthquakes.

Several microzonation studies performed in Italy in the last decades included geophysical investigations aimed at estimating the site response to earthquakes. A number of studies were commissioned by regional administrations in the framework of mid-term plans focused to seismic risk reduction, as for instance those made in Toscana Region (Regione Toscana et al. 2000), in Umbria Region, in the cities of Perugia (Boscherini et al. 2011) and Umbertide (Motti and Umbertide 2014), and in Marche Region for some historical towns (Mucciarelli and Tiberi 2004, 2007), respectively. For those studies, the seismic response was specifically estimated at sites hosting some strategic buildings, in order to gain useful knowledge for either evaluating the robustness of the overall emergency system or for improving the urban planning within a seismic risk reduction perspective. Other geophysical studies took place immediately after some destructive seismic sequences, in order to collect some significant pieces of information for possible subsequent studies of microzonation as well as providing indications for the next reconstruction of the damaged towns. Some examples of microzonation studies, which took advantage of such post-earthquake interventions, are those carried out after the seismic crises of 1997 in Umbria-Marche (Cattaneo and Marcellini 2000; Marcellini et al. 2001), 2002 at San Giuliano di Puglia (Baranello et al. 2003), 2009 in L'Aquila (MS-AQ Working Group 2010), 2012 in Emilia Romagna (Facciorusso 2012), respectively.

The Guidelines for Seismic Microzonation (Working Group 2008) recommend, for the Level 3, performing the assessment of local seismic response by the application of experimental or numerical techniques: the former are based on passive measures of either environmental seismic noise or strong- and/or weak-motion events, while the latter are based on 1-D and 2-D numerical simulations of seismic wave propagation.

In this work, we use earthquake recordings to evaluate the local site response. First of all, we carry out an expeditious comparison of the observed Peak Ground Velocity (PGV) and Spectral Amplitudes (SA) with those predicted by Ground Motion Prediction Equations (GMPEs). The main part of our study consists in the evaluation of the site response in terms of spectral amplification, which conceptually corresponds to the ratio between 
the spectrum of the ground motion observed at a given site during an earthquake and the ground motion that would be expected if the same site was on rock, without any effect of local geology on the seismic wavefield.

The spectral amplification is evaluated from the ground motion recordings of several events by using the Generalized Inversion Technique (Andrews 1986), hereafter GIT, a robust and flexible method that can be viewed as an extension of the Reference Site Spectral Ratio (Borcherdt 1970), by which the site seismic response is calculated as the spectral ratio to that of a rock site located nearby — the so called reference site-which is assumed to have neutral response. We also integrate the information obtained by GIT with those provided by two single station methods, i.e. the Receiver-Function technique (Lermo and Chávez-García 1994), which evaluates the site response from the spectral ratio between horizontal and vertical components of the ground motion recorded for earthquakes (hereafter indicated by EHV), and the Horizontal-to-Vertical Spectral Ratios, computed for ambient noise recordings acquired at the instrumented sites (hereafter indicated by NHV).

In this paper, we first describe briefly the Central Italy 2016-2017 seismic sequence and the geological framework of the area. Then, we describe the temporary network deployed by OGS. Finally, we show the results obtained by the analysis of the recorded data, and discuss them in the light of the geological features of the area.

\section{Outline of the seismic sequence and the geology of the area}

After the 2009 L'Aquila earthquake (Mw 6.1), the 2016-2017 seismic sequence has been the second disastrous event, which stroke the Central Italy in the last decade, involving tens of municipalities distributed among four different regions (Fig. 1a) and producing heavy damage, as well as about three hundreds of casualties.

The sequence started on August, 24th 2016 with the main Mw 6.0 earthquake occurred at 01:36 UTC near Accumuli, soon followed by the Mw 5.4 event at 02:33 UTC close to Norcia, at about $10 \mathrm{~km}$ of epicentral distance from the first shock (Michele et al. 2016). Then, the sequence migrated North of Norcia, in NNW direction, where three strong shocks with Mw 5.4, 5.9 and 6.5, respectively, occurred at the end of October 2016; later, it moved South of Accumuli, in SSE direction, releasing other four major earthquakes with Mw ranging from 5.0 to 5.5 on January, 18th 2017 (Fig. 1a).

Since August, 2016 until March, 2017, the National Seismic Network managed by INGV (Istituto Nazionale di Geofisica e Vulcanologia) located more than 1000 events with $\mathrm{M} \geq 3$ in an area (http://cnt.rm.ingv.it/) which extends for about $70 \mathrm{~km}$ from Muccia at North to Pizzoli at South, where it slightly overlaps the epicentral area of the 2009 L'Aquila earthquake (Fig. 1a).

The epicentral distribution of events is geometrically coherent with the extensional system of active faults longitudinally dissecting the Apennine chain (Boncio et al. 2004 and references therein), where most of the historical and instrumental seismicity is located.

The Time Domain Moment Tensor focal mechanisms of the strongest events are normal dip-slip with NNW-SSE striking focal planes (http://cnt.rm.ingv.it/tdmt), therefore compatible with the kinematic of those faults and the SW-NE trending tensional stress regime characterizing the Umbria-Marche-Abruzzo region (Ferrarini et al. 2015). Nevertheless, the depth distribution of hypocentres reveals the activation of a complex faults system, as suggested by early studies about the seismogenic source, which were 


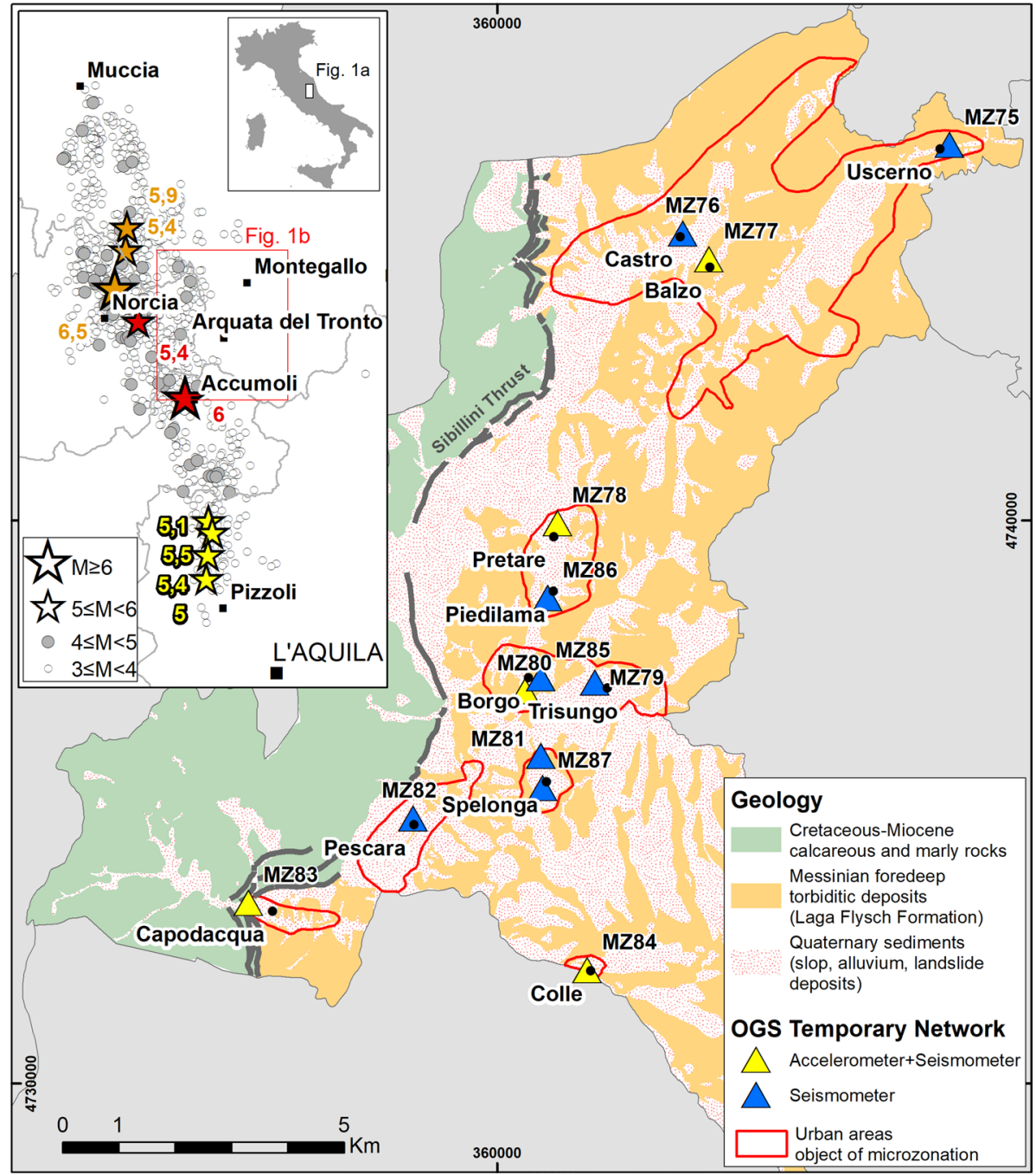

Fig. 1 Study area with the main geological features, the location of the temporary seismic network, and the epicenters of the earthquakes with $M \geq 3$ of the 2016-2017 Central Italy seismic sequence

mainly focused on the 24 August 2016 earthquake (Bonini et al. 2016; Lavecchia et al. 2016; Michele et al. 2016; Valensise et al. 2016).

From a geological point of view, the Central Italy 2016-2017 seismic sequence involved an area composed by two main domains separated each other by the Sibillini Thrust, a large tectonic discontinuity no more active (Di Domenica et al. 2012). The northwestern sector features Cretaceous-Miocene calcareous and marly rocks, while Messinian foredeep torbiditic deposits (Laga Flysch Formation) outcrop in the southeastern one. The OGS temporary stations were all located at the Sibillini Thrust footwall, on the Laga Flysch Formation often covered by Quaternary sediments. Therefore, the bedrock is represented within this study by one of the three members of the Laga 
Flysch Formation (arenaceous, arenaceous-pelitic and pelitic-arenaceous), although these lithotypes barely reach a shear wave velocity typical of a class-A soil (especially the last of the listed members).

\section{The OGS temporary network}

The OGS temporary seismic network was deployed in the epicentral area of August 24, 2016 mainshock, following the CMS indications in order to cover as many as possible severely damaged sites in the municipalities of Arquata del Tronto and Montegallo (Fig. 1). According to these suggestions, OGS installed ten temporary seismological stations within the small urban areas of the two villages from September 30, 2016 to November 25, 2016. A second phase followed from November 25, 2016 to February 17, 2017, in which six of the previous stations were closed and three additional new stations were opened, for a total of thirteen instrumented sites.

Three stations (MZ75, MZ76 and MZ77, respectively) were located in the municipality of Montegallo, while all the others (from MZ78 to MZ87) were installed in Arquata del Tronto. When possible, free field locations were preferred, even though we were sometimes forced to deploy the instruments at the basement of buildings for logistic conditions (e.g.: availability of electricity, urbanized environment, etc.). Particular care was devoted to the selection of the reference site, as it is crucial for spectral analyses. In the considered area the bedrock is represented by the arenaceous lithofacies of pre-evaporitic member of Umbria-Marche-Romagna-stratigraphic-succession named Laga Formation (Messinian p.p.), despite large carbonate blocks of paleo-landslides outcrop diffusely. Among the stations deployed on geological bedrock, i.e. MZ75, MZ77, MZ80 and MZ84 (Regione Marche-Carta Geologica Regionale 1:10.000), the site MZ75 located in Uscerno hamlet (Fig. 2a) was identified as the reference one in virtue of its flat NHV response. Unfortunately at the time of publication, we lack of more detailed geophysical data to support the choice of the reference site. The other sites are located on Quaternary sediments of different origin (alluvial, colluvial deposits, landslides, anthropic reports) laid on the different members of the Laga Formation.

From a morphological point of view, MZ76, MZ77 and MZ80 sites are located on the top of topographic irregularities (reliefs, ridges); MZ78, MZ79, MZ83 and MZ85 are set along narrow valleys; while the remaining sites are on the flank of hills (MZ75, MZ81, MZ82, MZ84, MZ86 and MZ87).

The equipment of our mobile stations consisted basically of a $1 \mathrm{~Hz}$ three-component velocimetric sensor (Lennartz 3Dlite) possibly buried in the soil, a datalogger set for continuous data acquisition with a sample rate of $100 \mathrm{~Hz}$, a GPS antenna and a battery connected to photovoltaic panels when power supply was not available. Five stations were equipped also with a strong-motion sensor: two of them with an Episensor accelerometer, the other three with a Nanometrics TitanXT strong motion accelerograph -a 6-channel model that incorporates the TXT-3 accelerometer- with real-time data transmission devices.

During the seismic crisis occurred in October 2016 all the accelerometric stations worked properly, while in January 2017 an exceptional snowfall covered the photovoltaic panels of some stations, interrupting the recording and preventing from recording the four M> 5 events occurred on January 18, 2017. 


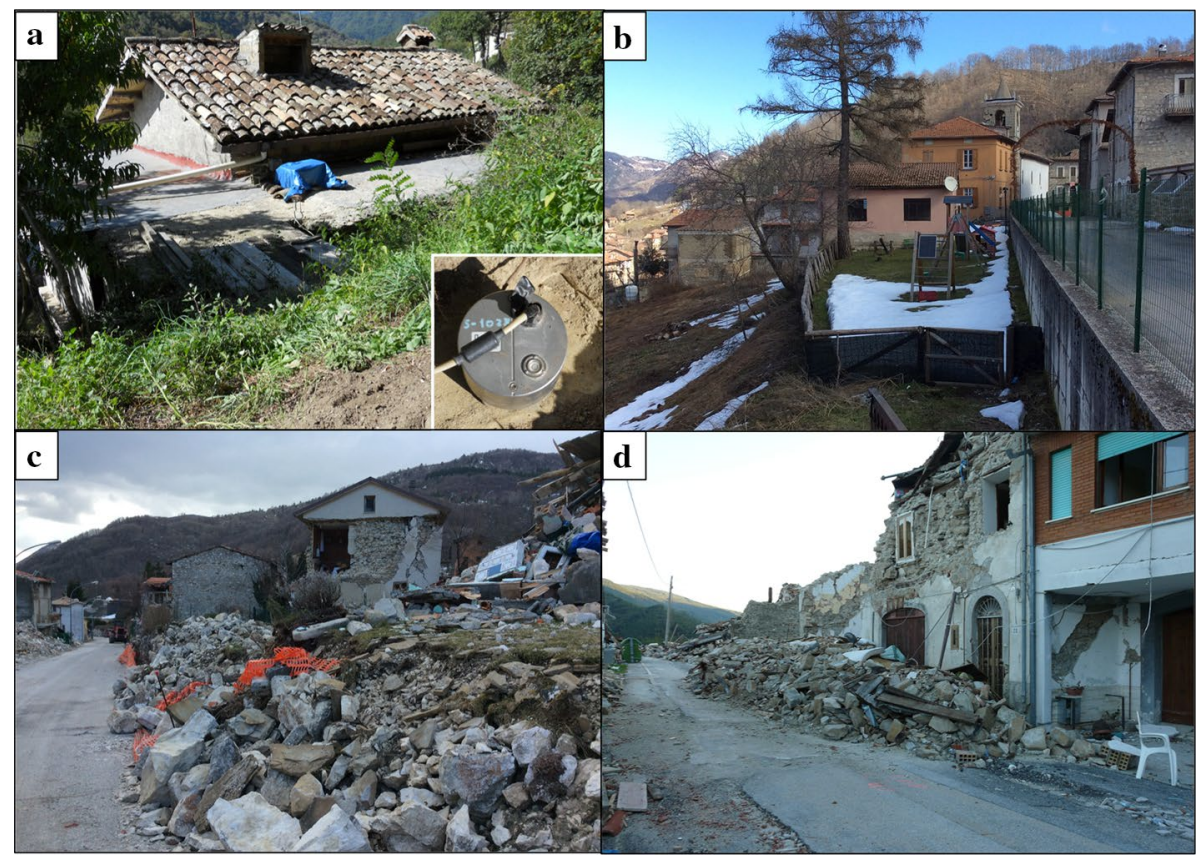

Fig. 2 a Reference site MZ75 located at the periphery of Uscerno village. The inset shows a detail of the sensor installation on the arenaceous association of Laga Formation. b MZ87 site, in the center of Spelonga, behind the church. The sensor is installed in the playground, buried in the soil under the red box, and the solar panel can be seen just above it. c-d Details of the damages at Pretare and Pescara del Tronto villages, where stations MZ78 and MZ82 have been installed, respectively

The main features of OGS temporary stations are summarized in Table 1; further details can be found in OASIS, the OGS Archive System of Instrumental Seismology (Priolo et al. 2015), under the network code MZ.

\section{Recordings}

As already said, accelerometers were installed at five out of thirteen sites. However, in this seismological study based on GIT technique, we make only use of recordings acquired by seismometers, not only to have homogeneity of instrumentation but also owing to a methodological reason. In fact, the source size of the only three $M>5$ earthquakes (i.e. the two Mw 5.4 and Mw 5.9 events, respectively, of 26/10/2016 and the Mw 6.5 event of $30 / 10 / 2016$ ) that saturated the seismometer recordings was too large, if compared to the short distance of the receivers, to satisfy the 'point source assumption' required by GIT.

Other authors make use of strong motion data to estimate source, path and site effects by GIT analysis, as for instance Castro et al. (2004) and Bindi et al. (2009a). In the mentioned studies, however, GIT was applied to a large dataset of stations sparsely located around the epicenters. In those cases, the possible effect due to the extended source (i.e. rupture directivity) affects only some but not all stations, and therefore it is shifted on the residuals. This is not our case, since our five accelerometric stations that recorded the three strongest 


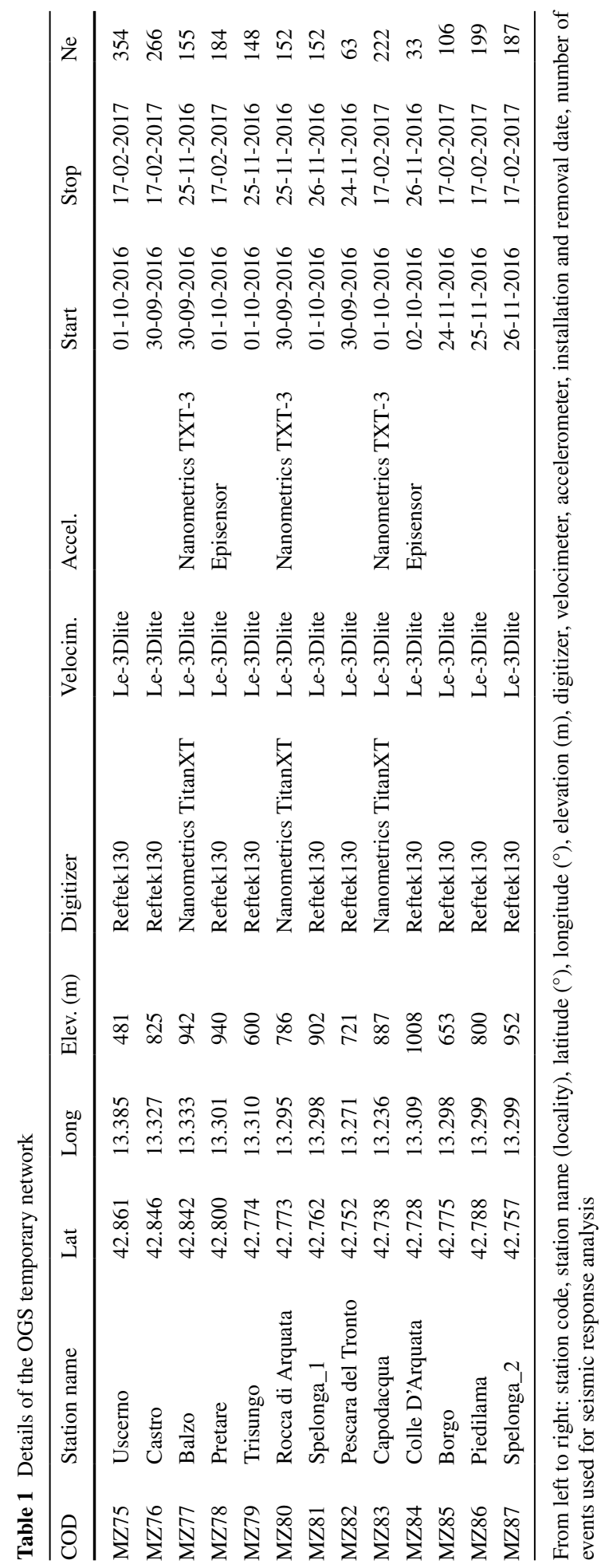


events (i.e the Mw 5.4 and Mw 5.9 of 26/10/2016, and the Mw 6.5 event of 30/10/2016) were all located at short distance from the extended fault, if not even above the fault surface itself-this is the case of the Mw 6.5 event-, and in any case within a somewhat narrow azimuth sector. Under this condition, GIT could fail in separating correctly the site and source effects. For all the other (weaker) events, we have verified that the accelerometric and seismometric recordings correspond each other in the frequency band analyzed in this study.

Earthquake recordings have been extracted from the continuous data flow, according to the list of events reported in the Italian Seismological Instrumental and parametric Database (ISIDe working group 2016). Data are processed by removing mean and linear-trend, band-pass filtering between 0.3 and $50 \mathrm{~Hz}$, instrument correction by poles and zeroes to obtain velocity time series. A visual inspection is performed in order to reject the recordings characterized by high noise level, spikes, overlapping seismic events and saturated time series.

About 6600 three-components recordings have been selected for the evaluation of site response. The selected recordings are related to 348 earthquakes with magnitude ML between 2.3 and 4.8 belonging to the Central Italy seismic sequence.

As already pointed out, GIT requires to satisfy two main conditions, i.e. that the pointsource approximation can be applied and that the used records satisfy the 'far-field' condition, respectively. Concerning the first one, we have already said that the record of the three largest events are excluded, since the size of the source is too large if compared to the receiver distances in those cases. About the latter, we remind that the 'far-field' condition can be defined as

$$
\frac{R}{\lambda} \gg 1
$$

where $\mathrm{R}$ is the event-station distance and $\lambda$ is the wavelength. According to Madariaga (2007), the far-field condition is satisfied at $R>10 \mathrm{~km}$ for frequencies $\mathrm{f} \geq 1 \mathrm{~Hz}$. An important issue is then to verify for which records this condition can be considered as satisfied. In our study, hypocentral depths range between about 8 and $12 \mathrm{~km}$, and epicentral distances are between few kilometres and $70 \mathrm{~km}$, with most of them between 10 and $40 \mathrm{~km}$. Thus, being the source-receiver distance nearly always larger than $15 \mathrm{~km}$, the far-field condition is satisfied for $\mathrm{f} \geq 0.5 \mathrm{~Hz}$. In order to verify the stability of the results against the epicentral distance, the spectral amplifications have been computed by GIT by considering the whole data set, only the events with epicentral distances larger than $15 \mathrm{~km}$ from the stations of the temporary network, and only the events with epicentral distances shorter than $15 \mathrm{~km}$, respectively. Figure 3 shows the locations of the epicenters of the three sets of events used for the computation of the spectral amplifications, with different detail. The full list of events is omitted here for the sake of brevity, and it can be found in Barnaba and Working Group (2017).

The continuous data recorded by the 13 stations of the temporary network are stored in OASIS. The user can retrieve detailed information about the seismological stations as well as download generic pieces of waveforms from the stream of continuous recordings through a dedicated web interface at the following address: http://oasis.crs.inogs.it. Continuous data are public. 


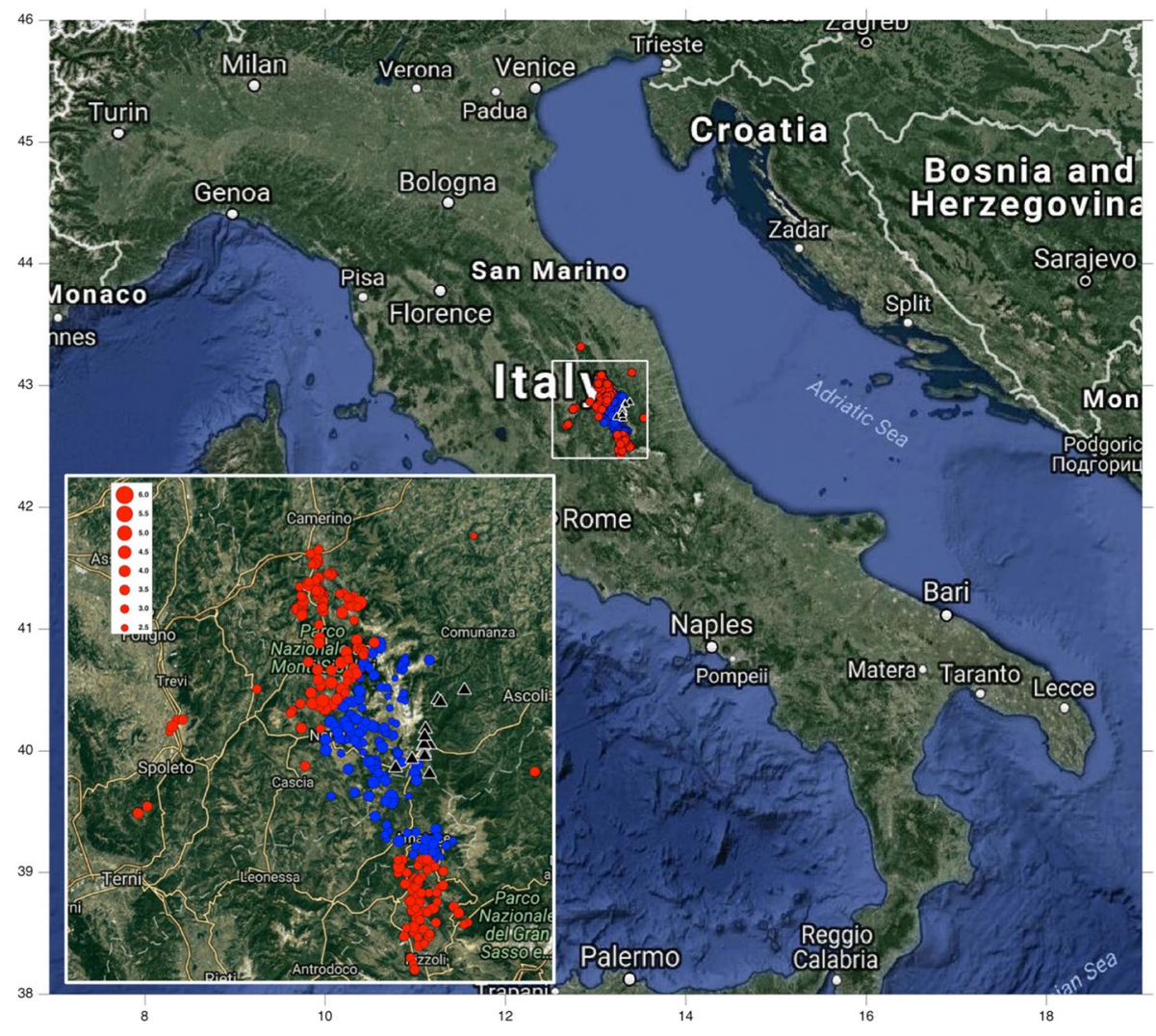

Fig. 3 Maps of the location of the 348 (red and blue circles) earthquakes used in the study and of the stations of the temporary network (black triangles), respectively. Red and blue circles are the events at distance larger and shorter than $15 \mathrm{~km}$ from the stations, respectively (see text for details)

\section{Site response analyses}

\subsection{Comparison of PGV with GMPE}

A first estimate of the ground motion site amplification is performed by comparing the PGV and the SA observed at the different sites with those predicted by the Ground Motion Prediction Equations (GMPEs) of Bindi, et al. (2011a) for EC8 soil class A and normal focal mechanism. Figure 4a shows the PGV observed at all the thirteen stations and those predicted by the GMPEs, represented by colored circles and curves, respectively. It should be noted that considered GMPEs of Bindi et al. (2011a) have been calculated for M>4. However, we decided to extend the analysis to $M>3$; otherwise the dataset of observations would be poor for some stations.

In order to better quantify this comparison, we compute also the ratio between the PGV observed at each station for each event and those predicted by the GMPEs at the same epicentral distance for an event of the same magnitude. This ratio (called $\alpha$ ) quantifies the amplification of the specific site with respect to a theoretical rock site, as predicted by the GMPE. In Fig. 4b we show the values of $\alpha$ obtained for site MZ75, which is located on 

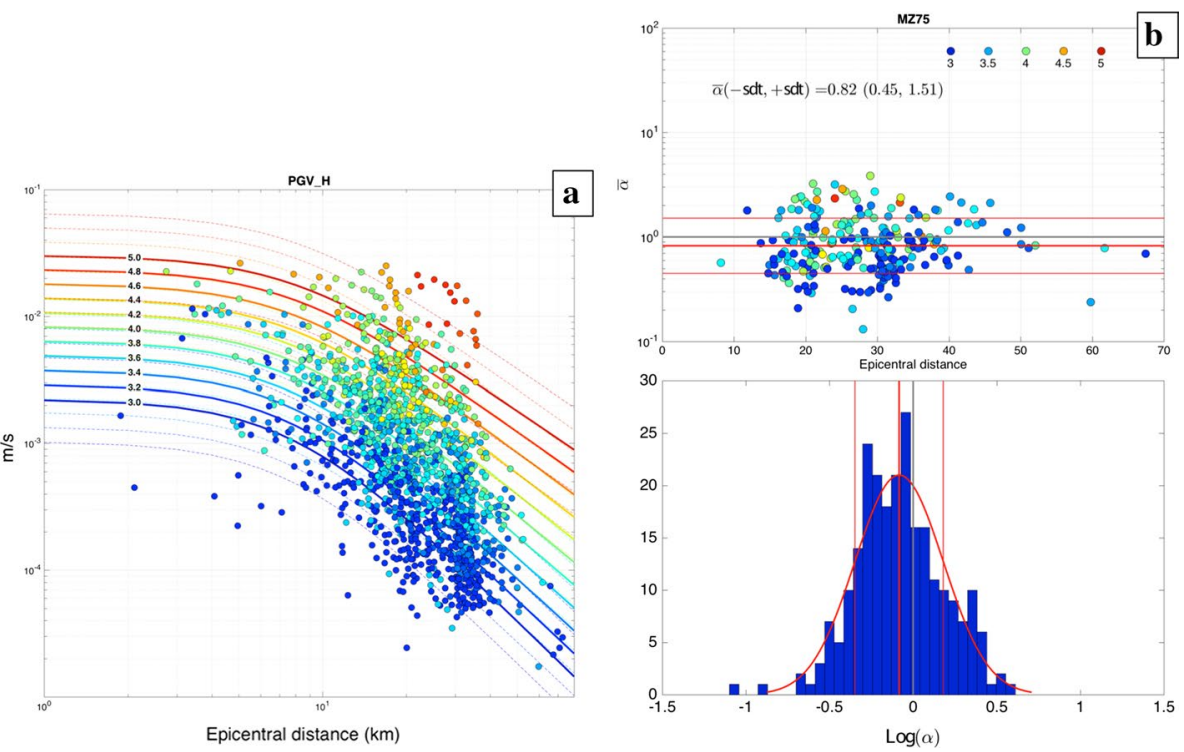

Fig. 4 a PGV values (circles) observed at all the thirteen stations versus the GMPEs (curves) of Bindi et al. (2011a). Colors indicate magnitude values. b PGV amplification at the MZ75 site. Top panel. Colored circles and red lines indicate the ratio $\alpha$ between the PGVs observed at the MZ75 site and those predicted by the GMPEs of (Bindi et al. 2011a), their mean and standard deviation, respectively. Circle colors indicate magnitude values. The grey horizontal line indicates the value one for reference. Bottom panel. Distribution of $\log (\alpha)$, mean and standard deviation

undisturbed sandstone of Laga Formation. It can be noticed that $\alpha$ does not depend on the event magnitude and follows a lognormal distribution. Those properties hold for all sites. For site MZ75 the mean value of $\alpha$ is less than one, namely 0.82 . We remind here that the constant value of 1 (grey line) represents the EC8 class A response, which corresponds to rock and has Vs30>800 m/s, according to Eurocode8 (CEN-Comité Européen de Normalisation 2004).

It should be noted that the amplification factors obtained from the analysis of a peak parameter (i.e. PGV) cannot be extended over the entire spectral bandwidth considered in
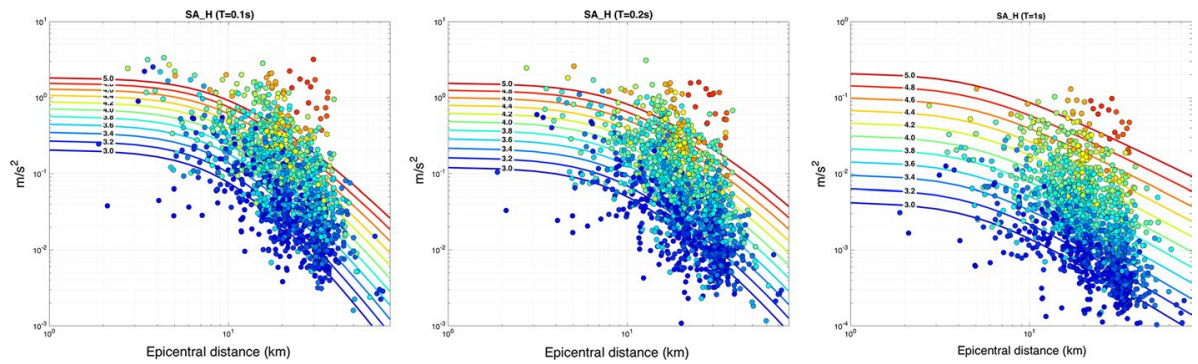

Fig. 5 SA values (circles) observed at all the thirteen stations versus the GMPEs (curves) of Bindi et al. (2011a). Colors indicate magnitude values. The reference period for SA is indicated on the top of each panel. Note that the $\mathrm{y}$-scale for SA $(\mathrm{T}=1.0 \mathrm{~s})$ is different from the others 
Table 2 Amplification values obtained for the thirteen sites

\begin{tabular}{lllll}
\hline & $\alpha(\mathrm{PGV})$ & $\alpha(\mathrm{SA}, \mathrm{T}=0.1)$ & $\alpha(\mathrm{SA}, \mathrm{T}=0.2)$ & $\alpha(\mathrm{SA}, \mathrm{T}=1.0)$ \\
\hline MZ75 & $0.8(1.5,0.4)$ & $1.1(2.2,0.5)$ & $0.7(1.4,0.3)$ & $0.8(1.4,0.4)$ \\
MZ76 & $2.1(4.1,1.1)$ & $3.4(6.8,1.7)$ & $2.2(4.4,1.1)$ & $1.5(2.8,0.8)$ \\
MZ77 & $1.1(2.2,0.5)$ & $1.2(2.4,0.6)$ & $1.4(2.9,0.6)$ & $1.0(1.9,0.5)$ \\
MZ78 & $1.6(3.5,0.7)$ & $1.5(3.2,0.6)$ & $1.9(4.5,0.8)$ & $1.4(2.8,0.6)$ \\
MZ79 & $0.8(1.7,0.4)$ & $1.3(2.6,0.6)$ & $0.7(1.6,0.3)$ & $0.7(1.4,0.3)$ \\
MZ80 & $1.3(2.7,0.6)$ & $1.5(3.3,0.6)$ & $1.4(3.1,0.6)$ & $1.5(3.1,0.7)$ \\
MZ81 & $1.6(3.3,0.8)$ & $2.3(5.3,1.0)$ & $1.5(3.2,0.7)$ & $1.9(4.0,0.9)$ \\
MZ82 & $2.4(4.6,1.2)$ & $3.0(5.9,1.5)$ & $3.8(8.2,1.7)$ & $2.2(3.7,1.2)$ \\
MZ83 & $1.4(2.8,0.7)$ & $3.0(6.0,1.3)$ & $1.8(4.0,0.8)$ & $0.9(1.7,0.4)$ \\
MZ84 & $0.8(1.8,0.3)$ & $0.8(2.1,0.3)$ & $0.9(2.2,0.3)$ & $0.8(1.9,0.3)$ \\
MZ85 & $0.9(1.7,0.4)$ & $1.2(2.3,0.6)$ & $1.2(2.6,0.6)$ & $0.7(1.1,0.4)$ \\
MZ86 & $1.3(2.5,0.6)$ & $1.7(3.8,0.7)$ & $1.1(2.4,0.5)$ & $1.0(1.7,0.5)$ \\
MZ87 & $0.9(1.8,0.5)$ & $1.2(2.6,0.6)$ & $0.9(1.7,0.4)$ & $1.6(2.8,0.8)$ \\
\hline
\end{tabular}

The following quantities are listed: mean value of obtained for PGV plus/minus the first standard deviation (in brackets) and for SA at three periods $(0.1,0.2$ and $1.0 \mathrm{~s})$

the study: in order to give a more complete indication of the amplification characteristics of the site, the same analysis has been performed also for the SA evaluated from the recordings at periods $\mathrm{T}=0.1,0.2$ and $1.0 \mathrm{~s}$, respectively. Figure 5 compares the SA obtained at all the thirteen stations to those predicted by the GMPEs. Similarly to the analysis performed for PGV, we computed for SA the mean value of $\alpha$. The amplification values obtained for the thirteen sites for PGV and SA are listed in Table 2. Apart from few cases, the highest (lowest) SA values are found for low (high) period $\mathrm{T}=0.1 \mathrm{~s}(\mathrm{~T}=1.0 \mathrm{~s})$. The remaining parameters ( $\mathrm{PGV}$ and $\mathrm{SA}$ at $\mathrm{T}=0.2 \mathrm{~s}$ ) lie between the first two, suggesting that PGV values could be related to an 'intermediate' frequency bandwidth. Table 2 evidences that other sites besides Uscerno (MZ75) are characterized by low amplification values (lower or near 1). These are Balzo (MZ77), Trisungo (MZ79), Colle d'Arquata (MZ84), Borgo (MZ85). On the other hand, sites such as Castro (MZ76) and Pescara del Tronto (MZ82) show the largest amplifications. The other sites are in the middle or display a high variability of these values.

\subsection{Spectral amplification}

For evaluating the spectral amplification we use GIT, a well-established, extremely flexible and robust tool, that can be viewed as an extension of the more direct approach Reference Site Spectral Ratio (Borcherdt 1970). The GIT was introduced by Andrews (1986) for seismic source analysis, and it has been used by many authors since then for many different applications ranging from microzonation studies (Parolai, et al. 2000) to seismic source analysis (Oth et al. 2009; Mandal and Dutta 2011) and crustal attenuation estimation (Oth et al. 2008).

In this study, we perform GIT analysis using GITANES (GIT ANalysis of Earthquake Spectra), a Matlab package that has recently been developed at OGS by some of the coauthors of this paper (Klin et al. 2017). 


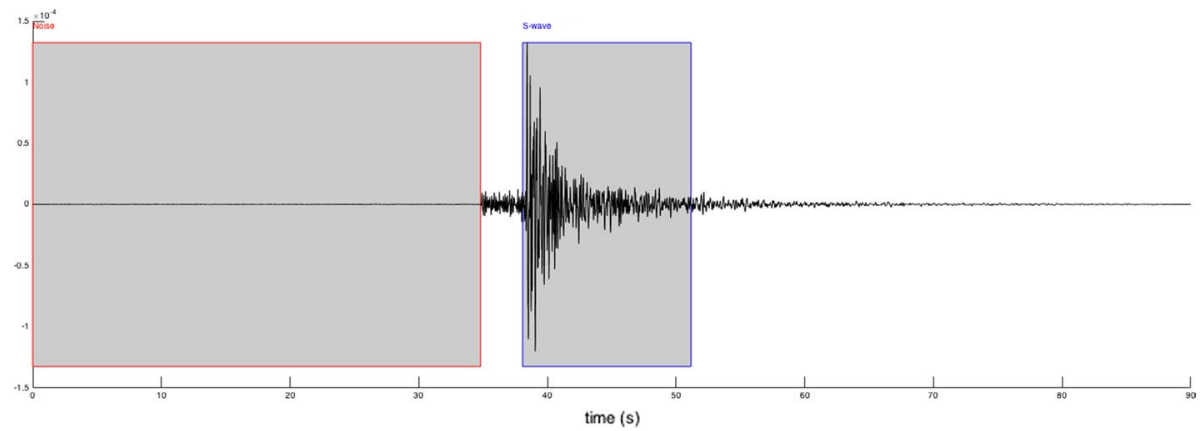

Fig. 6 GITANES Graphics Interface Screen: automatic selection of S-wave and pre-event noise windows (blue and red rectangles, respectively)

Earthquake recordings are processed for the analysis in the following way. The start of the $\mathrm{S}$-wave window is evaluated, from the picked P-wave arrival time, by applying the theoretical S-P time interval resulting from the event distance and the assumed Vs. Then a S-wave window is selected automatically, together with a $30 \mathrm{~s}$ of pre-event signal. The length of the $\mathrm{S}$-wave window is set 4 times the length of the S-P time interval. An example of S-wave and pre-event time windows is displayed in Fig. 6. For these windows, the Fourier amplitude spectra and a weight coefficient based on the signal-to-noise ratio are estimated. In essence GIT consists in finding a least squares solution. Considering that the data terms are affected by different levels of noise, we formulated GIT as a weighted least squares problem, in which the weight coefficients are evaluated on the basis of the signal to noise ratio (SNR) of seismic recordings. The SNR is evaluated as the ratio between the power spectra of the signal in the $\mathrm{S}$-wave window and in the pre-event window. All the details about the processing performed in GITANES can be found in Klin et al. (2017). The analyzed frequency range is $0.5-15 \mathrm{~Hz}$, which is adequate for the kind of instruments used in our survey and for the purposes of our study. Once the S-wave and pre-event signal time selection have been performed, then the GIT analysis is computed independently for all components.

In this study, we chose the Uscerno station (MZ75) as reference site. This site is located in the municipality of Montegallo and is characterized by the outcropping of the sandstone member of the Laga Flysch Formation that represents the seismic bedrock in this area. The NHV computed at this site is nearly flat.

In GITANES we consider the source and the seismic response terms as the unknowns of the problem. The propagation term is estimated on the basis of the propagation model and the known location of the seismic source. Assuming that the signal is dominated by S-waves, the simplest model of wave propagation implies that along the path from the $\mathrm{i}$-th event source to the $\mathrm{j}$-th site location at frequency $\mathrm{f}$, the logarithm of amplitude variation is:

$$
P\left(r_{i j}, f\right)=-\gamma \log \left(r_{i j}\right)-\frac{\pi f}{V_{S} Q_{S}(f)},
$$

where $\gamma$ is the geometrical spreading factor (ranges between $\gamma=1$ for spherical waves and $\gamma=0.5$ for cylindrical ones), $\mathrm{V}_{\mathrm{S}}$ is the $\mathrm{S}$-wave average velocity and $\mathrm{Q}_{\mathrm{S}}$ is the frequencydependent quality factor for S-waves. Here we assume the quality factor follows the conventional power-law:

$$
\mathrm{Q}_{s}(f)=\mathrm{Q}_{0} f^{\eta}
$$


where $Q_{0}=Q_{S}$ at $f=1 \mathrm{~Hz}$ and $\eta$ is a real parameter. In this work, we use parameter values specific for the Apennines, according to Malagnini et al. (2000): $V s=3.5 \mathrm{~km}, Q_{S}=130$, $\eta=0.1$ and $\gamma=0.9$ (for epicentral distances shorter than $30 \mathrm{~km}$ ). It should be emphasized that any deviation of the propagation model from that used can only cause errors on the source estimation (Parolai et al. 2000).

In addition to the spectral ratios computed by GIT, we also take into consideration the information provided by two techniques that do not use the reference site, i.e. the horizontal to vertical spectral ratios of S-waves and seismic noise, respectively. The first method, introduced by Lermo and Chavez-Garcia in 1993, calculates the spectral ratios between the horizontal and vertical component from earthquake recording at the same station. We call it EHV. This method relies on the assumption that the vertical component would not be subjected to the local site amplification, which would then allow to consider EHV as a sort of proxy of the spectral-ratio-to-reference-site approach. However, the previous assumption is questionable (Parolai and Richwalski 2004), and it is commonly acknowledged that this method is able to reveal the fundamental resonance frequency, but it may not provide a correct estimation of the amplification level. In this study, EHV spectral ratios have been evaluated from the Fourier Amplitude Spectra computed for the same S-wave windows of earthquake recordings extracted for the GIT analysis.

The second technique, indicated with NHV, computes the spectral ratio between the horizontal and vertical component from environmental seismic noise at the same station (Nogoshi and Igarashi 1970, 1971; Nakamura 1989). Owing to its simplicity-it uses a single station and it allows a significant reduction in time and cost of field-data acquisition-, NHV has become a widespread tool for the analysis of site effects. In the long lasting debate on the limitations of this methodology, the scientific community today agrees on the fact that NHV detects the fundamental resonance frequency of the site, but it cannot be used for either estimating the value of amplification or detecting higher resonant harmonics. In this study, NHV was calculated from a 60-min window of seismic noise extracted from the continuous recording at each seismological station. Particular attention was paid to the outliers' removal, e.g. earthquake signals, since acquisition had been carried out within the ongoing seismic sequence. The removal was manually performed by visual inspection of the time series and cutting of the outliers.

Figure 7 shows a summary of the spectral ratios computed for all the 13 sites. For each site, the top panel shows the spectral ratios obtained by the three methods used in this study, i.e. GIT, EHV, and NHV. The GIT spectral ratio refers to the horizontal component (hereafter GIT_H). The horizontal component is obtained for all the methods as the geometric mean of the two EW and NS horizontal components. Of course, the amplification functions obtained by GIT are relative to the adopted reference sites and their reliability depends on the adequateness of the latter. In this study, the reference site was found in the Uscerno village (station MZ75), in the northern sector of Montegallo municipality, where the arenaceous-pelitic member of the Laga Flysch formation outcrops. The NHV at this site exhibits the flattest curve among all the considered rock sites. No geophysical measurements of Vs30 are available at present.

As already mentioned, the GIT (black curves in Fig. 7) is computed for three datasets of events, namely the whole group of 348 events (GIT_H, blue and red circles in Fig. 3), a subset of 199 events (GIT_H_SEL1) with epicentral distance larger than $15 \mathrm{~km}$ from the nearest station (red circles in Fig. 3), and a subset of the remaining 149 events with epicentral distance shorter than 15 km (GIT_H_SEL2, blue circles in Fig. 3), respectively. We just mention here, that the analysis with the second group of events has not been performed for the station of Pescara del Tronto (MZ82), since large part of the distant events was not 
Fig. 7 Spectral ratios computed for all the 13 sites of this study. The description is provided for each panel. Top: spectral ratios obtained by GIT (horizontal component) for the whole set of events GIT_H (black continuous curve) and the two selections GIT_H_SEL1 and GIT_H_SEL2 (thick and thin black dashed curves, respectively), EHV and NHV (bold and thin red curves, respectively). The vertical line indicates the fundamental frequency estimated from NHV. Bottom: spectral ratios obtained by GIT (vertical component) for the whole set of events GIT_Z (black continuous curve) and the two selections GIT_Z_SEL1 and GIT_Z_ SEL2 (thick and thin black dashed curves, respectively). Only for the spectral ratios obtained by GIT for the whole dataset, the first standard deviation is shown (grey area) along the mean value

recorded due to some technical problems. As a general comment, the amplifications computed using the three datasets of events GIT_H, GIT_H_SEL1 and GIT_H_SEL2 (thick continuous black, thick dashed black and thin dashed black curves, respectively) provide very similar estimates. In particular, GIT_SEL1 and GIT_SEL2 provide values systematically lower and higher than GIT_H, respectively. However, the difference in amplitude between GIT_H_SEL1 and GIT_SEL2 is small and they are mostly included in the first standard deviation of GIT_H.

The comparison between the results obtained by the different methodologies is not trivial since the amplification curves often features rather complex shapes, sometimes with more than one peak and amplification extended over a broad frequency range. We estimate the fundamental frequency $\mathrm{f}_{0}$ from the NHV curve, if any, and report it explicitly in the panels of Fig. 7. We estimate $\mathrm{f}_{0}$ only from NHV since this is the measurement, which is usually performed in expeditious studies.

Except for site MZ87, for which site-to-reference-site method and single-station methods provide conflicting results, the comparison among GIT_H, EHV (thick red curve) and NHV (thin red curve) is very good in the low frequency band, i.e. up to the resonance frequency, whereas, at higher frequency, the three curves often deviate, with EHV showing systematically lower amplitudes than those obtained by GIT. The latter feature has been explained by Parolai and Richwalski (2004) as 'the effect of a transfer of energy onto the vertical component due to the S- to P-wave conversion'.

For each site in Fig. 7, the bottom diagram shows the GIT curves obtained for the vertical component for the three data sets of events (GIT_Z and GIT_Z_SEL1 and GIT_SEL2). Again, the agreement between the results obtained with the three datasets is very good. We notice that the vertical component of the motion is amplified for a number of sites, such as MZ76, MZ81, MZ82, MZ83 and MZ87, where amplification exceeds the value of 2. We also observe that the main GIT_Z peak is usually located at frequencies higher than that indicated by GIT_H. Note also that the frequency band around the peaks of the z-component corresponds to that which features the main discrepancies between GIT_H and the other two methods. In particular, the EHV and NHV curves usually feature a hole in correspondence of the peak of GIT_Z (see for instance sites MZ81, MZ82, MZ83, MZ86 and MZ87), as already observed by some authors in the past (e.g. Parolai and Richwalski 2004; Ameri et al. 2011). A clear example of the general inapplicability of single station methods, such as EHV or NHV, for evaluating the spectral amplification, is represented by site MZ87, where the results obtained by GIT_H show a specular trend with respect to NHV an EHV. In some cases, such as MZ79 and MZ84, respectively, GIT_V display very low value, below one for almost the entire frequency range. Note that for these two sites, the amplitude level of EHV and NHV significantly differs (i.e. is higher) from GIT_H.

Unfortunately, at the time of this study, no detailed geophysical information was yet available for the considered sites. For this reason, it was not possible to provide a detailed interpretation of the amplification curves obtained at the various sites. From the analysis of 

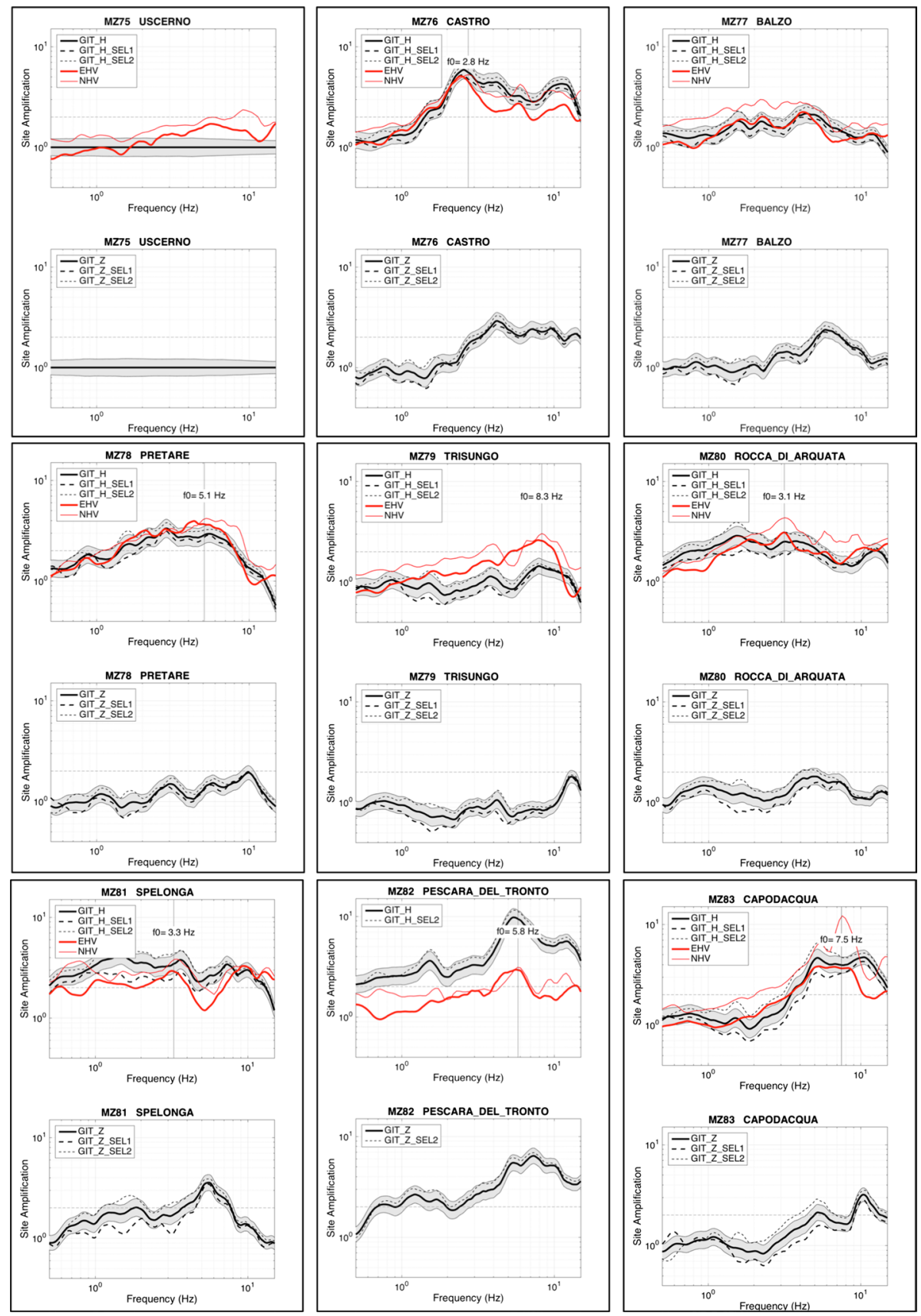

GIT_H, we can see that sites located on rock, i.e. on the Laga Flysch Formation (MZ75, MZ77, MZ80 and MZ84), feature nearly flat spectral ratios, without relevant peaks. All the other sites, which are characterized by Quaternary sediments of different origin and thickness that overlay the Laga Flysch Formation, feature amplification in the mid-high 

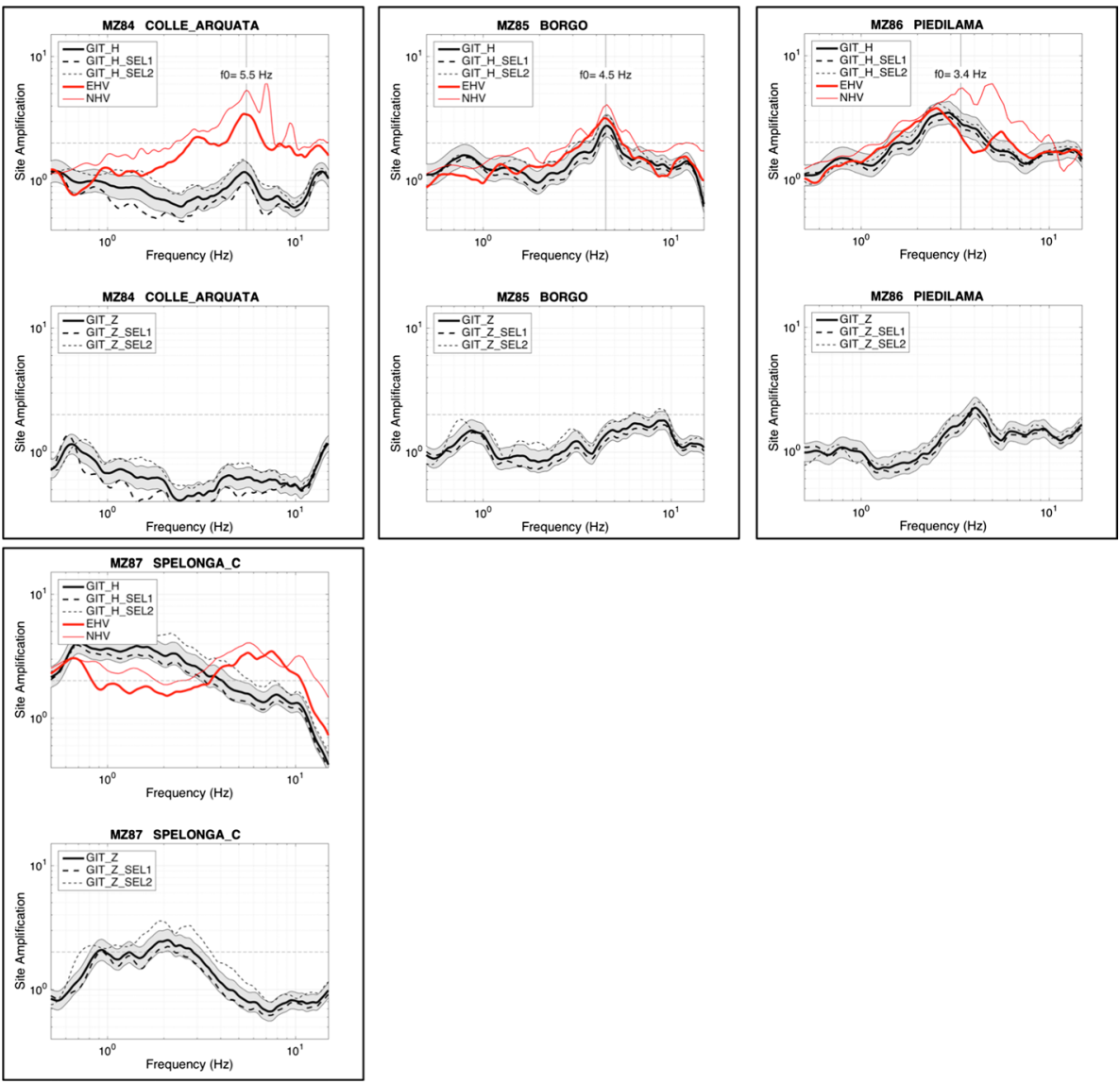

Fig. 7 (continued)

frequency range, generally between 2 and $10 \mathrm{~Hz}$. Amplification exceeding 2 are obtained at MZ78, MZ81, MZ85 and MZ86, while amplitudes near or greater than 3 are achieved instead at sites MZ76, MZ82, MZ83 and MZ87. Some sites feature broad-band amplification: for example the MZ78 site of Pretare, displays a broad 'peak', with amplitudes higher than two for frequencies between 1.4 and $8.2 \mathrm{~Hz}$. This wide amplification can be traced back to a number of causes, i.e. a low impedance contrast, some irregular underground interfaces or in general 2-D or 3-D effects as well as the effects of locally induced surface waves as observed by Bindi et al. (2009b, 2011b) at sites located on alluvial basins. Since the village of Pretare is built on the deposits of an ancient landslide, with a varying laterally thickness, and we do not observe any evidence of significant surface wave contribution in the recordings, we can just hypothesize that this amplification is due to the local heterogeneity of the underground structure.

Before combing the two horizontal components, we first checked them separately: for all the sites, except one, MZ80, the curves obtained for the NS and EW components do not differ substantially and, for the sake of clearness, only their average has been shown in Fig. 7. The amplification curves obtained for MZ80 site for the two horizontal components 

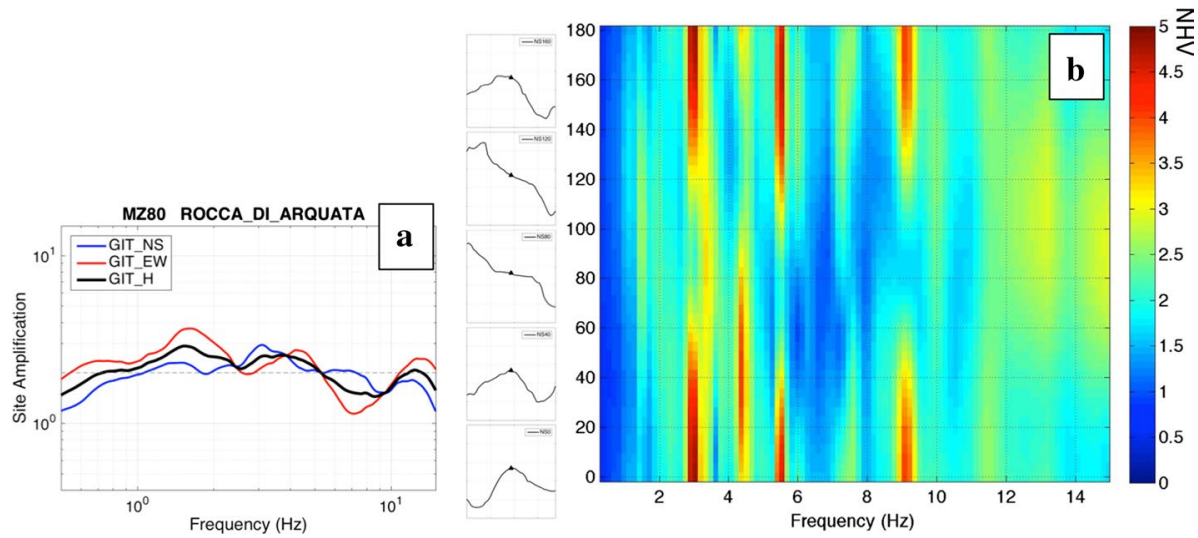

Fig. 8 a Spectral ratios obtained by GIT at the site MZ80 (Rocca di Arquata). The red, blue and black curves represent the amplifications obtained for the NS, EW and mean horizontal components, respectively. b Directional NHV computed for the MZ80 site. At left, the topographic profiles crossing the site and corresponding to $0^{\circ}, 40^{\circ}, 80^{\circ}, 120^{\circ}$ and $160^{\circ}$ from North are plotted

is shown on panel a of Fig. 8 (red and blue curves). It is clear that the two components diverge significantly, with curves characterized by peaks and holes while their average (black curve) does not feature pronounced peaks but an amplification value between 2 and 3 on almost the entire frequency range. The MZ80 station was deployed at the base of a medieval castle, overlooking the village of Arquata del Tronto. The village develops along an elongated ridge about WE oriented, formed by the different lithotypes (arenaceous and arenaceous-pelitic) of the Laga Formation. In order to investigate the observed discrepancy between the two horizontal components, a directional analysis of NHV was performed at this site. Results (Panel b of Fig. 8) display a clear polarization in the NS direction, almost perpendicular to the ridge direction, which therefore cannot be a consequence of 1-D resonance effects but which may be caused by topography or rather by a resonance frequency of the nearby castle's towers. A more detailed analysis will be needed for investigating the exact cause of these directional resonance effects.

We eventually compare the spectral response obtained by GIT with the index $\alpha$ estimated by the PGV and SA analysis. To do that, we compute the site coefficients as reported by Borcherdt (2002), i.e. as the arithmetic average for the horizontal components of the site-to-reference (rock-)site Fourier amplitude spectral ratio over two period-bands representing the short (0.1-0.5 s) and medium periods (0.4-2.0 s), respectively. We compute site coefficients from GIT_H using the whole dataset (i.e. black continuous curves in Fig. 7) by the arithmetic mean on equi-spaced periods.

The resulting values, for all 13 sites and the two period-bands, are shown and compared to $\alpha$ in Fig. 9. On one hand, it can be noticed the overall similar behavior of all the coefficients: sites characterized by some significant amplifications always emerge, as well as those characterized by weak amplification. However, there are some remarkable differences that should be discussed. First of all, the sites at which the site coefficients do not agree (in particular for MZ82, MZ83, and MZ87) correspond to those for which the GIT_H ratio varies significantly among the considered period-bands. Then, a very good agreement can be noticed between the behavior of the mid-period band site coefficients (FA_mp and $\mathrm{SA}$ for $\mathrm{T}=0.2 \mathrm{~s}$ ) and that obtained from PGV, but for a scaling factor. Three sites MZ75 


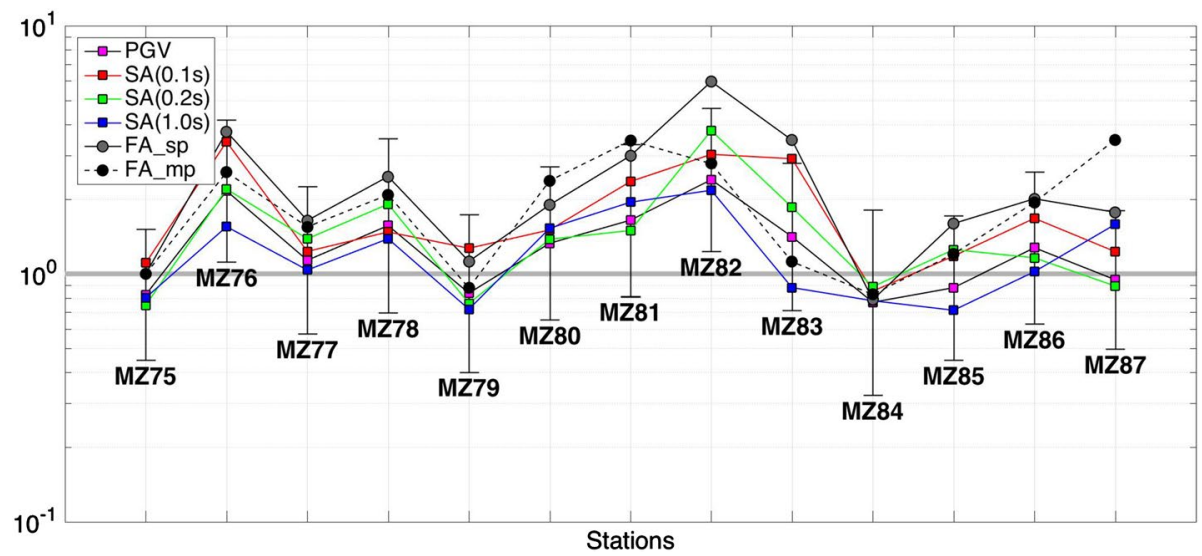

Fig. 9 Scalar values of amplification computed for the thirteen sites analyzed in this study. The following quantities are represented: amplification values $\alpha$ for PGV (magenta squares connected by black continuous line) plus/minus the first standard deviation (vertical bars) and for SA at periods $0.1,0.2$ and $1.0 \mathrm{~s}$, respectively (in the order: red, green and blue squares connected by black lines); site amplification coefficient FA_sp and FA_mp, computed according to Borcherdt (2002), for the 0.1-0.5 s short-period band and the 0.4-2.0 s mid-period band, respectively (in the order: grey circles connected by grey continuous line, and black circles connected by black dashed line, respectively). The thick grey horizontal line indicates the value one, as a reference of the neutral response

(Uscerno), MZ77 (Balzo) and MZ84 (Colle D'Arquata) located on the Laga Formation feature values of all the coefficients near or lower than 1, which indicates a neutral response. For MZ80, also located on rock, but, as seen, characterized by directional amplification (perhaps due to topography), PGV and all SA feature low values $(<2)$, in contrast with the quite high values of both FA_sp and FA_mp.

The site coefficients computed from the amplification curves for the short period band FA_sp are almost always larger than the amplification factors computed for PGV and SA. Two exceptions are the two Spelonga sites (MZ81 and MZ87) for which the maximum amplitude is reached by FA_mp: this difference can however be explained with a medium-high level of amplification on the whole band, and especially in the medium-low band $(\mathrm{f}<2-3 \mathrm{~Hz})$, a feature that characterizes only these two stations (see Fig. 7).

The site characterized by the highest values is MZ82, Pescara del Tronto. The village (Fig. 2), built on Quaternary deposits of anthropic origin, was one of the most damaged sites on August 24, 2016, with many collapses (Fig. 2, panel d) and 48 fatalities. It features a very high level of amplification with amplitudes near 10 at about $6 \mathrm{~Hz}$ (Fig. 7). A preliminary study performed by Masi et al. (2016) found similar resonance frequencies in the NHV (between 4 and $6 \mathrm{~Hz}$ ) and attributed the different damage distribution in Pescara del Tronto in comparison with the nearby village of Vezzano mainly to local site effects rather than to the seismic vulnerability of the buildings.

In general, none of the computed coefficients do represent the amplification in the whole frequency band; however this is an obvious comment if we consider that each coefficient "samples" the spectral ratios at some specific period-band. 


\section{Conclusions}

We evaluate the seismic response of thirteen sites located in the municipalities of Arquata del Tronto and Montegallo, which were heavily damaged during the Central Italy 2016-2017 seismic sequence. This study uses the data recorded by a seismic temporary network in a period of about 5 months (October 2016-February 2017), when the seismic sequence was ongoing.

The estimation of the seismic response is performed by the Generalized Inversion Technique (referred to as GIT) and uses a reference site located on rock. The GIT results are compared in the frequency domain with those obtained by two single-station techniques, i.e. EHV and NHV, respectively. In addition, two scalar site coefficients are computed for two different period-bands, respectively, and they are compared with the mean ratio between the PGV and the SA observed at the sites and those predicted by GMPEs for a class-A soil.

The comparison between the local site responses obtained by different approaches and different subsets of data shows in general a very good agreement.

Differences between reference site (GIT_H) and single-station methods (EHV and NHV) can be ascribed to the amplification level of the vertical component. The spectral site response of the 13 examined sites features the largest amplification in the mid-high frequency band, generally between 2 and $10 \mathrm{~Hz}$, and is characterized by a large variability over the investigated area. Sites with significant amplification level are: Castro (MZ76), Pretare (MZ78), Pescara del Tronto (MZ82) and Capodacqua (MZ83); they are all located on Quaternary deposits overlying the bedrock. The MZ81 and MZ87 sites (in the Spelonga hamlet) are the only sites characterized by amplification in the medium-low band $(\mathrm{f}<2-3 \mathrm{~Hz}$ ). Sites characterized by low or no amplification are: MZ75 (Uscerno), Balzo (MZ77), Trisungo (MZ79), Colle d'Arquata (MZ84) and Borgo (MZ85). Directional amplification due to topography has been probably identified at MZ80 site (Rocca di Arquata).

Acknowledgements This study has been performed within the framework of the OGS intervention set up during the seismic sequence that followed the Mw 6.0 August 24, 2016 Central Italy earthquake and regulated by specific agreement between the Institute of Environmental Geology and Geo-Engineering of the National Research Council (CNR - Istituto di Geologia Ambientale e Geoingegneria) and the OGS. All actions were coordinated by the CMS - Centro di Microzonazione Sismica e sue applicazioni on request of DPC-Department of Civil Protection. We wish to thank the Italian Fire Brigade (Corpo Nazionale dei Vigili del Fuoco) for the care and logistic support provided to the OGS personnel within the "red zone", the Civil Protection volunteers and the local people who kindly allowed us hosting the instruments in their homes. We also thank Dino Bindi and the anonymous reviewer for their comments and suggestions, which have been really useful to improve our article.

Open Access This article is distributed under the terms of the Creative Commons Attribution 4.0 International License (http://creativecommons.org/licenses/by/4.0/), which permits unrestricted use, distribution, and reproduction in any medium, provided you give appropriate credit to the original author(s) and the source, provide a link to the Creative Commons license, and indicate if changes were made.

\section{References}

Ameri G, Oth A, Pilz M, Bindi D, Parolai S, Luzi L, Mucciarelli M, Cultrera G (2011) Separation of source and site effects by generalized inversion technique using the aftershock recordings of the 2009 L'Aquila earthquake. Bull Earthq Eng 9:717-739. https://doi.org/10.1007/s10518-011-9248-4

Andrews DJ (1986) Objective determination of source parameters and similarity of earthquakes of different size, in Earthquake source mechanics. In: Das S, Boatwright J, Scholz CH (eds) American Geophysical Monograph 37, vol 6, pp 259-267

Baranello S, Bernabini M, Dolce M, Pappone G, Rosskopf C, Sanò T, Cara PL, De Nardis R, Di Pasquale G, Goretti A, Gorini A, Lembo P, Marcucci S, Marsan P, Martini MG, Naso G (2003) Rapporto finale 
sulla Microzonazione Sismica del centro abitato di San Giuliano di Puglia. Dipartimento di Protezione Civile, Roma

Barnaba C, Working Group (2017) Campagna sismometrica di Arquata-Montegallo 2016-2017. Valutazione della risposta sismica locale dei comuni di Arquata del Tronto e Montegallo (AP). Rel. 2017/36 Sez. CRS 11. 28 Aprile 2017. http://www2.ogs.trieste.it:8585/biblioteca/

Bindi D, Pacor F, Luzi L, Massa M, Ameri G (2009a) The Mw 6.3 2009 L'Aquila earthquake: source, path and site effects from spectral analysis of strong motion data. Geophys J Int 179(3):1573-1579. https:// doi.org/10.1111/j.1365-246X.2009.04392.x

Bindi D, Parolai S, Cara F, Di Giulio G, Ferretti G, Luzi L, Monachesi G, Pacor F, Rovelli A (2009b) Site amplifications observed in the Gubbio Basin, Central Italy: hints for lateral propagation effects. Bull Seismol Soc Am 99(2A):741-760. https://doi.org/10.1785/0120080238

Bindi D, Pacor F, Puglia R, Massa M, Ameri G, Paolucci R (2011a) Ground motion prediction equations derived from the Italian strong motion data. Bull Earthq Eng 9(6):1899-1920. https://doi.org/10.1007/ s10518-011-9313-z

Bindi D, Luzi L, Parolai S et al (2011b) Site effects observed in alluvial basins: the case of Norcia (Central Italy). Bull Earthq Eng 9(6):1941-1959. https://doi.org/10.1007/s10518-011-9273-3

Boncio P, Lavecchia G, Pace B (2004) Defining a model of 3D seismogenic sources for Seismic Hazard Assessment applications: the case of central Apennines (Italy). J Seismol 8(3):407-425

Bonini L, Maesano FE, Basili R, Burrato P, Carafa MMC, Fracassi U, Kastelic V, Tarabusi G, Tiberti MM, Vannoli P, Valensise G (2016) Imaging the tectonic framework of the 24 August 2016, Amatrice (central Italy) earthquake sequence: new roles for old players? Ann Geophys 59:1-10. https://doi. org/10.4401/ag-7229

Borcherdt RD (1970) Effects of local geology on ground motion near San Francisco Bay. Bull Seismol Soc Am 60:29-61

Borcherdt RD (2002) Empirical evidence for site coefficients in building-code provisions. Earthq Spectra 18:189-218

Boscherini A, Motti A (a cura di) (2011) La microzonazione sismica del Comune di Perugia. Regione Umbria, Servizio Geologico e Sismico-Comune di Perugia, Settore Governo e Sviluppo del Territorio e dell'Economia 31-41

Castro RR, Pacor F, Bindi D, Luzi L (2004) Site response of strong motion stations in the Umbria, Central Italy, Region. Bull Seismol Soc Am 94(2):576-590. https://doi.org/10.1785/0120030114

Cattaneo M, Marcellini A (A cura di) (2000) Terremoto dell'Umbria-Marche:-Analisi della sismicità recente dell'Appennino umbro-marchigiano.-Microzonazione sismica di Nocera Umbra e Sellano, CNR-Gruppo Nazionale per la Difesa dai Terremoti-Roma, 2000, 228 pp. +CD-ROM allegato

CEN-Comité Européen de Normalisation (2004) Eurocode 8: Design of Structures for earthquake resistance-Part 1: General rules, seismic actions and rules for buildings. EN 1998-1, CEN, Brussels

Di Domenica A, Turtù A, Satolli S, Calamita F (2012) Relationships between thrusts and normal faults in curved belts: new insight in the inversion tectonics of the Central-Northern Apennines (Italy). J Struct Geol 42:104-117

Facciorusso J (2012) Microzonazione sismica: uno strumento consolidato per la riduzione del rischio. L'esperienza della Regione Emilia-Romagna. Bologna, IT: Centro Stampa Regione Emilia-Romagna. http://ambiente.regione.emilia-romagna.it/geologia/divulgazione/pubblicazioni/sismica/microzonaz ione-sismica-uno-strumento-consolidato-per-la-riduzione-del-rischio.-12019esperienza-della-regioneemilia-romagna

Ferrarini F, Lavecchia G, de Nardis R, Brozzetti F (2015) Fault geometry and active stress from earthquakes and field geology data analysis: the Colfiorito 1997 and L'Aquila 2009 Cases (Central Italy). Pure appl Geophys 172(5):1079-1103. https://doi.org/10.1007/s00024-014-0931-7

ISIDe Working Group (2016) Version 1.0. https://doi.org/10.13127/iside

Klin P, Laurenzano L, Priolo E (2017) GITANES: A MATLAB package for joint estimation of site spectral amplification and seismic source spectra with the generalized inversion technique. Seismol Res Lett 89(1):182-190. https://doi.org/10.1785/0220170080

Lavecchia G, Castaldo R, Nardis R, De Novellis V, Ferrarini F, Pepe S, Brozzetti F, Solaro G, Cirillo D, Bonano M, Boncio P, Casu F, De Luca C, Lanari R, Manunta M, Manzo M, Pepe A, Zinno I, Tizzani P (2016) Ground deformation and source geometry of the 24 August 2016 Amatrice earthquake (Central Italy) investigated through analytical and numerical modeling of DInSAR measurements and structural-geological data. Geophys Res Lett. https://doi.org/10.1002/2016GL071723

Lermo J, Chávez-García F (1994) Are microtremors useful in site response evaluation? Bull Seismol Soc Am 84:1350-1364

Malagnini L, Herrmann RB, Di Bona M (2000) Ground-motion scaling in the Apennines (Italy). Bull Seismol Soc Am 90(4):1062-1081 
Mandal P, Dutta U (2011) Estimation of earthquake source parameters in the kachchh seismic zone, Gujarat, India, from strong-motion network data using a generalized inversion technique. Bull Seismol Soc Am 101(4):1719-1731. https://doi.org/10.1785/0120090050

Marcellini A, Daminelli R, Tento A, Franceschina G, Pagani M (2001) The Umbria-Marche microzonation project: outline of the project and the example of Fabriano results. Italian Geotech J 2:28-35

Masi A, Santarsiero, G, Chiauzzi, L, Gallipoli MR, Piscitelli S, Vignola L, Bellanova J, Calamita G, Perrone A, Lizza C, Grimaz S (2016) Different damage observed in the villages of Pescara del Tronto and Vezzano after the M6.0 August 24, 2016 central Italy earthquake and site effects analysis. Ann Geophys 59(5). https://doi.org/10.4401/ag-7271

Michele M, Di Stefano R, Chiaraluce L, Cattaneo M, De Gori P, Monachesi G, Latorre D, Marzorati S, Valoroso L, Ladina C, Chiarabba C, Lauciani V, Fares M (2016) The Amatrice 2016 seismic sequence: a preliminary look at the mainshock and aftershocks distribution. Ann Geophys 59(5). https://doi. org/10.4401/ag-7227

Motti A, Gruppo di lavoro Microzonazione Sismica di Umbertide (2014) La microzonazione sismica dell'area di Umbertide, Publisher: Regione Umbria, Italy, Editors: Motti A., pp. 69-78 (in Italian)

MS-AQ Working Group (2010) Microzonazione Sismica per la ricostruzione dell'area Aquilana. Regione Abruzzo. Dipartimento di Protezione Civile, L’Aquila, 3 Vol \& CD-rom (in Italian)

Mucciarelli M, Tiberi P (a cura di) (2004) Microzonazione sismica: Cagli-Offida—Serra de' ContiTreia., Regione Marche, Gruppo Nazionale per la Difesa dai Terremoti, Istituto Nazionale di Geofisica e di Vulcanologia, Ancona. pp. 69+Allegati +CD

Mucciarelli M, Tiberi P (a cura di) (2007) Scenari di pericolosità sismica della fascia costiera marchigiana-La microzonazione sismica di Senigallia, Regione Marche-Istituto Nazionale di Geofisica e di Vulcanologia, Ancona. pp. 294 + Allegati + CD

Nakamura Y (1989) A method for dynamic characteristics estimation of subsurface using microtremor on the ground surface. QR Railway Tech Res Inst 30:25-33

Nogoshi M, Igarashi T (1970) On the propagation characteristics estimations of subsurface using microtremors on the ground surface. J Seismol Soc Jpn 23:264-280

Nogoshi M, Igarashi T (1971) On the amplitude characteristics of microtremor (Part 2). J Seismol Soc Jpn 24:26-40

Oth A, Bindi D, Parolai S, Wenzel F (2008) S-wave attenuation characterisitcs beneath the vrancea region in Romania: new insights from the inversion of ground-motion spectra. Bull Seismol Soc Am 98(5):2482-2497. https://doi.org/10.1785/0120080106

Oth A, Parolai S, Bindi D, Wenzel F (2009) Source spectra and site response from S waves of intermediatedepth Vrancea, Romania, earthquakes. Bull Seismol Soc Am 99(1):235-254

Parolai S, Richwalski SM (2004) The importance of converted waves in comparing H/V and RSM site response estimates. Bull Seismol Soc Am 94:304-313

Parolai S, Bindi D, Augliera P (2000) Application of the Generalized Inversion Technique (GIT) to a microzonation study: numerical simulations and comparison with different site estimation techniques. Bull Seismol Soc Am 90(2):286-297

Priolo E, Laurenzano G, Barnaba C, Bernardi P, Moratto L, Spinelli A (2015) OASIS-The OGS archive system of instrumental seismology. Seismol Res Lett 86(3):978-984. https://doi.org/10.1785/02201 40175

Regione Marche «CARTA GEOLOGICA-PROGETTO: "UNICO TERRITORIALE GEOLOGICO” 1:10.000. »www.ambiente.marche.it

Regione Toscana, Dip.to delle politiche territoriali ed ambientali, U.O.C. Rischio sismico (2000) Valutazione degli effetti locali, Programma VEL-Istruzioni tecniche per le indagini geologico-tecniche, le indagini geofisiche e geotecniche, statiche e dinamiche finalizzate alla valutazione degli effetti locali nei comuni classificati sismici, 'Progetto Terremoto' in Garfagnana e Lunigiana, atto di programmazione negoziata tra Regione Toscana e Dipartimento della Protezione Civile, Firenze

Valensise G, Vannoli P, Basili R, Bonini L, Burrato P, Carafa MMC, Fracassi U, Kastelic V, Maesano FE, Tiberti MM, Tarabusi G (2016) Fossil landscapes and youthful seismogenic sources in the central Apennines: excerpts from the 24 August 2016, Amatrice earthquake and seismic hazard implications. Ann Geophys 59(5). https://doi.org/10.4401/ag-7215

Working Group SM (2008) Instructions and criteria for seismic microzonation. In: Conference of the regions and autonomous provinces of Italy-Civil Protection Department. http://www.protezionecivil e.gov.it/jcms/it/view_pub.wp?contentId=PUB1137. Accessed June 2017 